\title{
Mobile Money and School Participation: Evidence from Africa
}

\author{
Valentina Rotondi ${ }^{1,2,3,5}$ (D) Francesco C. Billari $i^{3,4}$
}

Received: 26 August 2020 / Accepted: 23 January 2021 / Published online: 14 February 2021

(c) The Author(s) 2021

\begin{abstract}
This paper shows that mobile money technology —an electronic wallet service that allows users to deposit, transfer, and receive money using their mobile phonesis positively correlated with increased school participation of children in school age. By using data from 4 African countries, we argue that, by reducing transaction costs, and by making it easier and less expensive to receive remittances, mobile money reduces the need for coping strategies that are detrimental to child development, such as withdrawing children from school and sending them to work. We find that mobile money increases the chances of children attending school. This finding is robust to different empirical models. In a nutshell, our results show that 1 million children could start attending school in low-income countries if mobile money was available to all.
\end{abstract}

Keywords Mobile money $\cdot$ School $\cdot$ Child labor $\cdot$ Technology $\cdot$ Digital revolution

Mathematics Subject Classification $\mathrm{O} 16 \cdot \mathrm{O} 17 \cdot \mathrm{G} 20 \cdot \mathrm{O} 33$

Valentina Rotondi

valentina.rotondi@sociology.ox.ac.uk

1 Department of Sociology, University of Oxford, Oxford, UK

2 Nuffield College, Oxford, UK

3 Dondena Centre for Research on Social Dynamics and Public Policy, Bocconi University, Milan, Italy

4 Department of Social and Political Sciences, Bocconi University, Milan, Italy

5 Department of Business Economics, Health and Social Care, University of Applied Sciences and Arts of Southern Switzerland, Lugano, Switzerland 


\section{Introduction}

According to the latest available data, two billion people worldwide are still unbanked, i.e., they do not have access to an account at a formal financial institution (The World Bank 2015). Expanding access to financial services is a crucial factor in poverty reduction, as it facilitates saving and borrowing. Saving and borrowing help in coping with transitory income shocks, by reducing households' needs to resort to strategies that might be detrimental for their members in the longer term (Munyegera and Matsumoto 2016) such as selling livestocks. These coping strategies often involve children, who might have to be withdrawn from school and sent to work in order to support their household.

Mobile money technology, an electronic wallet service that allows users to deposit, transfer, and receive money using their mobile phones, is deemed as a way to extend financial services to the unbanked, especially in remote and rural areas. Thanks to the expansion of mobile phones, this financial innovation has spread rapidly in low-income countries (Suri and Jack 2016).

Mobile money facilitates the exchange of peer-to-peer remittances and promotes informal risk sharing among family members and friends in different ways: by reducing transaction costs; by providing secure and affordable opportunities for savings even in remote areas; and by reducing security risks associated with cash payments (Mbiti and Weil 2011). Therefore, one could expect mobile money to be linked to higher opportunities to smooth consumption in the face of temporary shocks (Jack and Suri 2014; Munyegera and Matsumoto 2016), to reduce food insecurity (Murendo and Wollni 2016), and to increase financial resilience, savings (Suri and Jack 2016; Ky et al. 2017), and household disposable income (Kikulwe et al. 2014).

In this paper, we study a potential pathway through which mobile money can enhance development, i.e., school participation of children in school age. Although universal education has been widely recognized as a key building block for sustainable development and a prerequisite for ending poverty and hunger (Lutz 2017), this goal is far from being reached. In several low-income countries, children still constitute an important source of income either directly (through involvement in formal wage employment) or indirectly (through involvement in domestic activities, particularly hazardous chores). Furthermore, in the absence of efficient credit markets, children are often seen as a buffer against shocks, such as production shocks or illness of a household member (Dehejia and Gatti 2005; Beegle et al. 2006; Guarcello et al. 2010; Dillon 2013). ${ }^{1}$ According to the latest available data, in the the world's poorest countries around one in four children (ages 5 to 17) were engaged in activities that were detrimental to their development with Sub-Saharan Africa having the highest prevalence of child labor $(29 \%){ }^{2}$

Although child labor has declined (Clark 2011), much remains to be done to achieve the fourth Sustainable Development Goal ("Ensure inclusive and equitable

\footnotetext{
1 For a recent review of the literature see (Fors 2012).

${ }^{2}$ https://data.unicef.org/topic/child-protection/child-labour.
} 
quality education and promote lifelong learning opportunities for all") by 2030. Working children still account for almost $11 \%$ of the child population as a whole (Edmonds and Pavcnik 2005) and the global number of children of primary school age not attending school has remained almost stable over the past five years (UNESCO 2016).

With this paper we contribute to the literature on child labor, school attendance, and to the growing literature on the adoption of digital technology and mobile money in low-income countries, by empirically showing that, by making it easier and less costly to receive remittances and to save money, mobile money technology reduces the need for child labor as a way to self-insure households, especially the most vulnerable, against unexpected shocks. Mobile money therefore contributes to increasing investments in children's human capital, and to reduce the probability that a household does not send children to school (Suri and Jack 2016). To the best of our knowledge, among the growing amount of empirical studies examining the effect of mobile money, no one has explicitly focused on this topic yet. In a nutshell, our findings, based on InterMedia's Financial Inclusion set of nationally representative sample surveys on Kenya, Nigeria, Tanzania, and Uganda ${ }^{3}$, suggest that households using mobile money services are significantly less likely to have children in school age that do not attend school. These results are robust to the use of different estimation techniques and model specifications. Furthermore, we show that the effect of mobile money is, at least for girls, significantly higher for more vulnerable households.

\section{Conceptual Framework}

Children in low-income countries are often seen as risk-coping instruments (De Janvry et al. 2006) that sustain households' consumption during hard times by working in the labor market, by cultivating households' land, or by substituting parents in households' chores and in caring for their younger siblings. The overwhelming consensus in the literature ${ }^{4}$ is that child labor is rooted in poverty and that, all else equal, parents prefer to send their children to school and dislike to send them to work if they can afford to do so (Basu et al. 2010), the so-called luxury axiom in Basu and Van's model (Basu and Van 1998). As a result, the link between income and school participation appears to be strong enough to be taken for granted $^{5}$ : assuming a standard model of allocation of time with schooling and leisure being normal goods, when income increases, schooling and leisure increase as well, while (the

\footnotetext{
3 These surveys cover seven countries in Africa (Kenya, Nigeria, Tanzania, and Uganda) and Asia (Bangladesh, India, and Indonesia). Since mobile money penetration is higher in Africa, compared to Asia, we focus only on the 4 African countries included in the sample.

4 Relevant exceptions are, among others, (Bhalotra and Heady 2003) introducing the concept of a "wealth paradox," (Kambhampati and Rajan 2006), (Dumas 2007) and (Kruger 2007).

5 Note that, however, the relationship between school participation, child labor and income is not always linear. As an example, (Basu et al. 2010) have formally and empirically shown that the relationship between wealth and child labor exerts an inverted-U shape. Notice also that together with economic forces, also cultural forces, such as gender norms, also matter for child labor (Delap 2001; Rankin and Aytaç 2006).
} 
need for) child labor decreases ${ }^{6}$. Accordingly, when capital and insurance markets are imperfect (e.g., Baland and Robinson 2000; Ranjan 2001; Pouliot 2006), or in presence of short-term fluctuations in wages, income, or economic growth (Soares et al. 2012), child labor increases and schooling decreases.

There are at least two pathways through which mobile money can be related to reduced child labor and increased school participation. First, mobile money technology makes it easier to receive remittances. A growing literature shows that remittances, by serving as an additional income source, can have a positive effect on investment in children's education (Adams and Cuecuecha 2013; Mendola 2016; Bargain and Boutin 2015a; Tabetando and Matsumoto 2020) and, under given conditions, a positive effect in terms of reducing child labor (Bargain and Boutin 2015b; Coon 2016; Binci and Giannelli 2016; Azizi 2018). The literature also shows that remittances improve the educational outcomes of girls more than the educational outcomes of boys (Azizi 2018). ${ }^{7}$ Absent mobile money, remittances can be sent through banking services, or sent through people traveling to their destination (Kikulwe et al. 2014). While banks, when available, are safe enough, sending remittances through personal contacts (i.e., the bus driver traveling to his daily route) is associated with high transaction costs (including corruption and extortion) and is less safe. Mobile money, being a relatively faster and safer financial service innovation, can therefore be seen as the easiest and fastest way to receive remittances, especially in rural areas where financial institutions are often missing and connecting infrastructures with neighboring and more developed realities are often lacking. According to Vasconcelos (2017), an estimated amount of US\$ 6.5 trillion will be sent to low- and middle-income countries between 2015 and 2030. More than 10\% of this amount will be used to cover long-term goals such as education and health. ${ }^{8}$

Second, mobile money, by serving as an electronic wallet that provides a safe although non-remunerated savings instrument, can increase savings. These savings may free up some money which can be spent on education. In the absence of saving vehicles, such as bank accounts, households resort to less-efficient strategies such as

\footnotetext{
${ }^{6}$ Note that school participation and child labor are not always mutually exclusive (Edmonds and Pavcnik 2005) — especially when considering intra-household child work (Hazarika and Bedi 2003) —, however, children that leave school or that do not attend school at all are less likely to go back to school due to higher entrance costs, included social stigma.

7 The literature on the effect of remittances on development (conceptualized in a broad sense) is growing rapidly. As we have already seen above, this literature shows that there is a positive relationship between remittances and education. Beyond this, the literature shows that remittances ultimately decrease poverty and inequality (Azizi 2019) while they increase financial development in developing countries (Azizi 2020). We thank an anonymous referee for having suggested these readings.

${ }^{8}$ In Africa, total remittances amounted to 60.5 US\$ billion in 2016 up from 44.3 in 2007, a $36 \%$ increase. Among the 4 countries analyzed in this paper, Kenya saw a growth in the volume of remittances between 2007 and 2016 equal to $167.7 \%$, Uganda to $138.6 \%$, Nigeria to 5.2\%. Data for Tanzania are not available.
} 
the purchase of assets or durables that can be sold to the market during hard times (Edmonds and Shrestha 2014). Although households with a sufficiently high level of assets are able to cope with transitory income shocks (Beegle et al. 2006), they could have less money to invest in education, a cost of around 1.25 USD a day per child in low-income countries (UNESCO 2015).

The simple models presented above imply that households' decision to send children to school does not depend on children's gender. However, this is not always the case (see for instance Björkman-Nyqvist 2013; Rankin and Aytaç 2006). In many countries, girls continue to face several barriers to get education. According to Filmer (2005), three motivations are behind this gender gap in education that should be accounted for in theoretical and empirical models. First, the direct costs and, second, the opportunity costs of education may differ by gender. In fact, although in almost all regions, boys and girls are equally likely to be involved in child labor, children play different roles in household production. ${ }^{9}$ While girls usually look after their siblings, and help in household's chores, boys are usually employed in cultivating family's land or in waged jobs. The opportunity costs of schooling therefore crucially depend on the relative importance of each one of these two roles. Third, the returns to the investment in education may also differ by gender (Barro and Lee 2013).

Given the conceptual framework outlined above, we can formulate the following three hypotheses that we test with our data:

H1 Mobile money is positively associated with schooling in Africa

$\mathrm{H} 2$ The association between mobile money and schooling is more salient for more vulnerable households for which a relatively cheap and simple innovation such as mobile money can have significantly higher socio-economic consequences.

H3 The association between mobile money and schooling is greater for boys with respect to their girls counterparts for which waged jobs are less relevant.

\section{Materials and Methods}

\section{Data}

Our empirical analysis is based on cross-sectional data from 2015 and 2016 from the InterMedia's Financial Inclusion surveys ${ }^{10}$ on Kenya, Nigeria, Tanzania, and Uganda. ${ }^{11}$ The data set contains detailed information on mobile phones, banks, mobile money, and non-bank financial institutions, focusing in particular on awareness, access, and use. The survey includes information on household composition, poverty status, as well as other geographic and demographic measures. The survey

\footnotetext{
9 https://data.unicef.org/topic/child-protection/child-labour.

$10 \mathrm{http}$ ///finclusion.org/.

11 The survey originally covers Nigeria, Tanzania, Kenya, Uganda, Indonesia, Pakistan, India, and Bangladesh. We restrict the sample to African countries since they are characterized by higher penetration rates of mobile money. The main results are unchanged when using the full set of available countries.
} 
Table 1 Summary statistics

\begin{tabular}{|c|c|c|c|c|}
\hline Variable & Mean & $\mathrm{SD}$ & Min. & Max. \\
\hline \multicolumn{5}{|l|}{ Main dependent variables } \\
\hline The household has boys not going to school & 0.08 & 0.28 & 0 & 1 \\
\hline The household has girls not going to school & 0.08 & 0.27 & 0 & 1 \\
\hline \multicolumn{5}{|l|}{ Main explanatory variable } \\
\hline Active Mobile Money (mm) user & 0.34 & 0.47 & 0 & 1 \\
\hline \multicolumn{5}{|l|}{ Further explanatory variables: mechanisms } \\
\hline Mobile money: remittances & 0.1 & 0.3 & 0 & 1 \\
\hline Mobile money: savings & 0.08 & 0.27 & 0 & 1 \\
\hline \multicolumn{5}{|l|}{ Covariates } \\
\hline Receive Gov. benefits & 0.05 & 0.22 & 0 & 1 \\
\hline Own a bank account & 0.24 & 0.43 & 0 & 1 \\
\hline The household has savings & 0.55 & 0.5 & 0 & 1 \\
\hline The household has insurance & 0.09 & 0.28 & 0 & 1 \\
\hline Number of household members $>18$ earning income & 1.86 & 1.11 & 0 & 10 \\
\hline Number of household members & 4.46 & 2.53 & 1 & 24 \\
\hline Shock: weather & 0.28 & 0.45 & 0 & 1 \\
\hline Shock: natural disaster & 0.11 & 0.31 & 0 & 1 \\
\hline Shock: costs of inputs & 0.2 & 0.4 & 0 & 1 \\
\hline Shock: price of crop or livestock & 0.18 & 0.38 & 0 & 1 \\
\hline Relocated & 0.23 & 0.42 & 0 & 1 \\
\hline The household lives below the poverty line & 0.67 & 0.47 & 0 & 1 \\
\hline \multicolumn{5}{|l|}{ Robustness } \\
\hline Share of boys (school age) not enrolled in school & 0.14 & 0.32 & 0 & 1 \\
\hline Share of girls (school age) not enrolled in school & 0.14 & 0.32 & 0 & 1 \\
\hline \multicolumn{5}{|l|}{ Characteristics of the household head } \\
\hline Rural female & 0.17 & 0.37 & 0 & 1 \\
\hline Literacy & 0.77 & 0.42 & 0 & 1 \\
\hline Numeracy & 0.96 & 0.19 & 0 & 1 \\
\hline \multicolumn{5}{|l|}{ Instruments } \\
\hline Knows mobile money service & 0.53 & 0.5 & 0 & 1 \\
\hline Access to an Over The Counter (OTC) & 3.72 & 1.68 & 1 & 6 \\
\hline
\end{tabular}

InterMedia's Financial Inclusion surveys from Kenya, Nigeria, Tanzania, and Uganda. Individuals 15 years and older who declare to have at least one child aged 18 years or below in their household

is limited to individuals 15 years and older. Our sample is composed of 30,377 respondents $^{12}$ of which roughly 21,948 declare to have at least one child aged 18 years or below in their household. We limit the analysis to the latter sub-group of households.

12 Kenya (5994), Nigeria (12,353), Tanzania (6030), and Uganda (6000). 
Descriptive statistics for the variables used in the empirical analysis are depicted in Table 1.

Our two main dependent variables are dummy variables taking value one if the household has children (either boys or girls) in school age ${ }^{13}$ that do not attend school (The household has boys/girls not going to school). As a robustness check, we also compute for each household the share of children (either boys or girls) in school age that do not attend school (Share of boys/girls not enrolled in school). ${ }^{14}$ In order to avoid confounding effects, we exclude from these measures children that do not attend school because of illness or disability (around 3\% of the children in school age). Overall, $8 \%$ of the households has boys or girls that do not attend school even if they are in school age. This estimate hides, however, significant differences across countries, with Tanzania and Uganda overcoming Kenya and Uganda with around 1 over 5 households having children in school age that do not attend school. Although it is not always easy to access data on child labor at the country-level in low-income countries, our data are consistent with descriptive statistics collected by UNICEF, World Bank and International Labor Organization ${ }^{15}$.

Mobile money use (Active mm user) is a binary variable that equals one if at least one member of the household is an active user of mobile money services, zero otherwise. This variable considers therefore both registered and non-registered users. Overall, $34 \%$ of the respondents declare to be users of mobile money services. As shown in Fig. 1, these rates vary substantially across countries, with Kenya and Nigeria displaying, respectively, the highest (73\%) and lowest (1\%) rate, consistently with international data on mobile money adoption (GSMA 2017). ${ }^{16}$

Figure 2, computed on the whole sample, offers a simple assessment of the association of mobile money use with school participation. Overall, the pattern that emerges is that mobile money is negatively associated with the presence of out-ofschool children.

\section{Methods}

Our main approach is to estimate the association between mobile money and schooling assuming that the probability that a household has children in school age that do not attend school $(S)$-or, equivalently, the share of children in the household in school age that do not attend school,- - of household $h$ in country $c$, depends on mobile money usage $(M M)$ and a vector $X$ of individual and household-level controls:

$$
S_{\mathrm{hc}}=\beta_{0}+\beta_{1} \mathrm{MM}_{\mathrm{hc}}+X_{\mathrm{hc}}+\lambda_{c}+\lambda_{y}+\varepsilon_{\mathrm{hc}}
$$

\footnotetext{
13 School age is defined on the basis of the regulations in force in each Country.

14 Note that this variable is calculated only for households having at least one child in school age.

15 See, for instance, http://www.ucw-project.org.

16 https:/www.gsma.com/mobilefordevelopment/wp-content/uploads/2017/03/GSMA_State-of-theIndustry-Report-on-Mobile-Money_2016-1.pdf.
} 


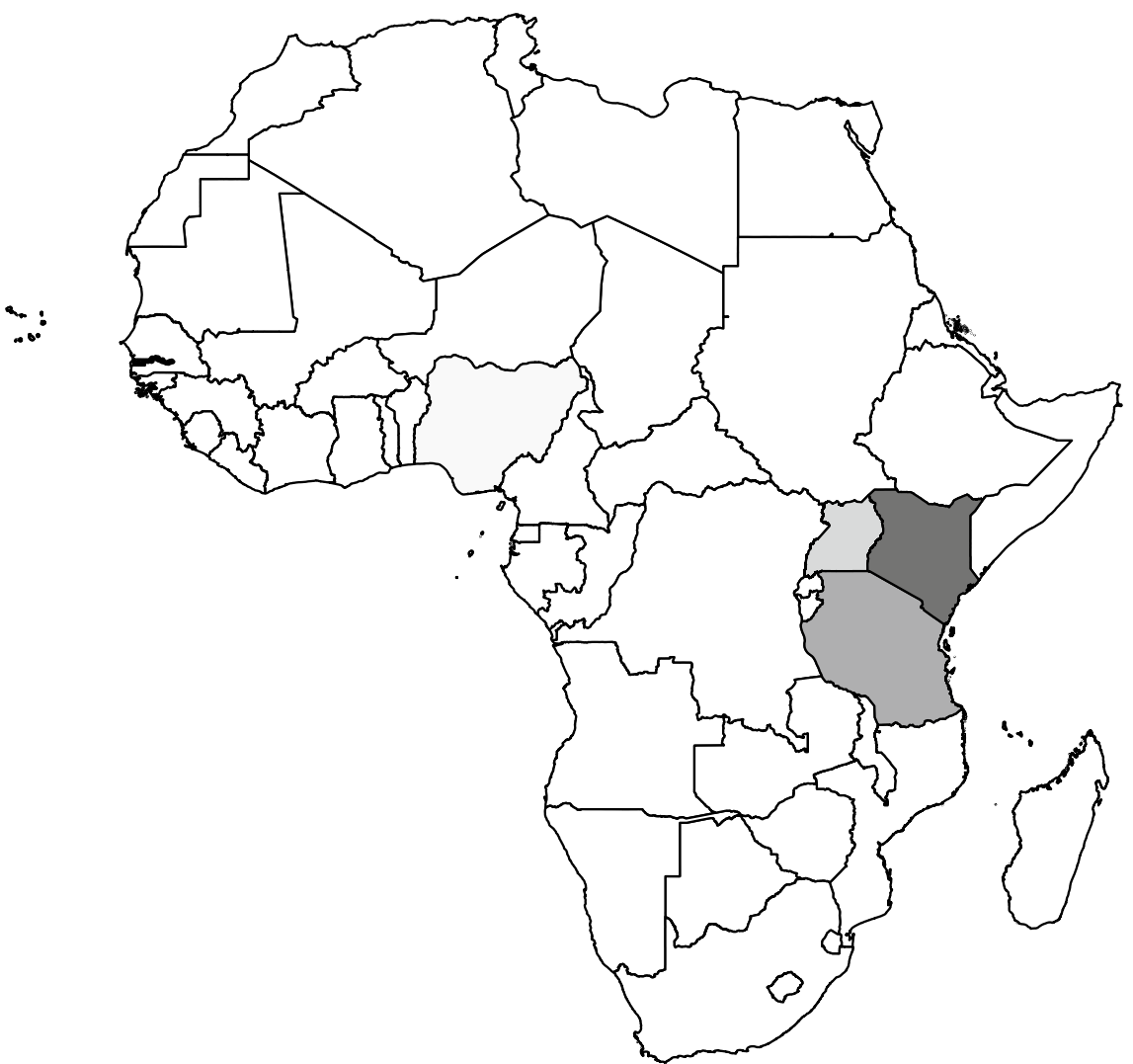

Fig. 1 Mobile money penetration (\%), by country

In Eq. (1), $\lambda_{c}$ and $\lambda_{y}$ represent country and year fixed effects, respectively, so as to account for possible heterogeneity across different countries and years, and $\varepsilon_{\mathrm{hc}}$ the error term. As covariates in the different models $(X)$, we include several household characteristics which would affect mobile money usage by accounting for the likelihood that a household is living below the poverty line (The household lives below the poverty line),${ }^{17}$ household size, the number of adults in the household that earn an income, household's use of financial services other than mobile money (a bank account, an insurance, any type of savings including savings and credit cooperatives and associations), and whether the household has experienced in the last 12

\footnotetext{
17 Specifically, we make use of the Progress out of Poverty Index (http://www.progressoutofpoverty .org/), a poverty measure obtained by 10 questions about a household's characteristics and asset ownership scored to compute the likelihood that the household is living below the poverty line.
} 

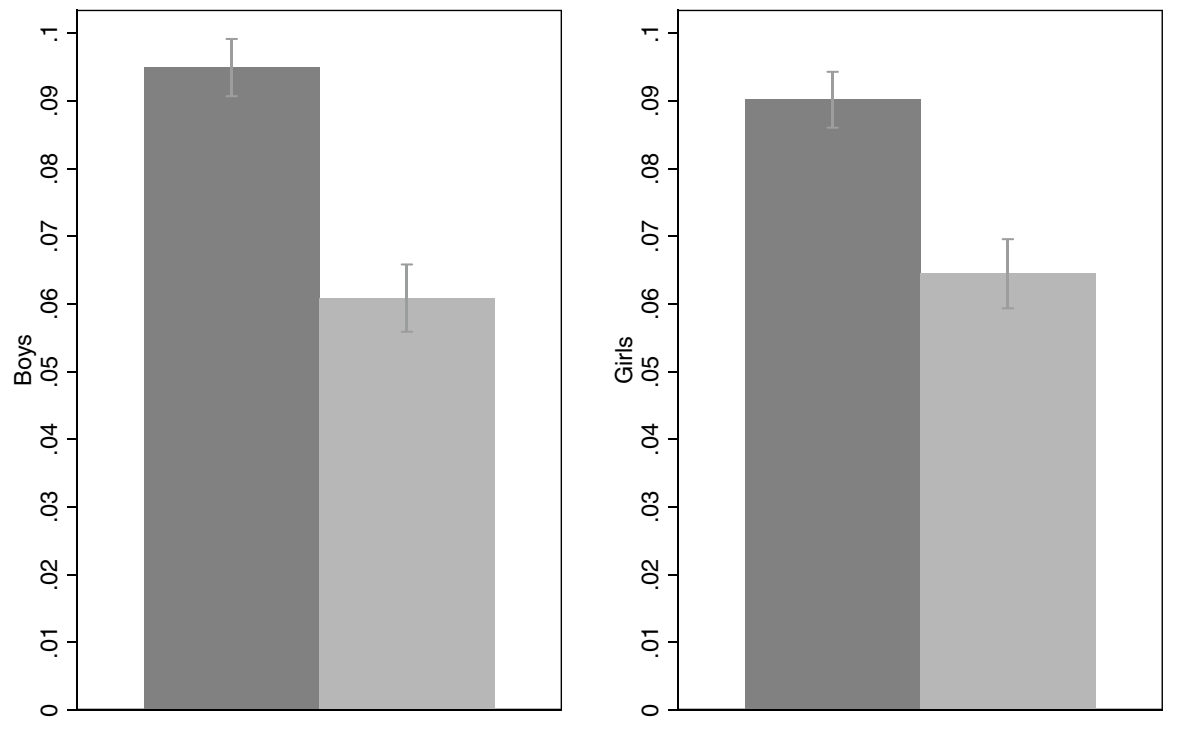

No mobile money

Mobile money

Fig. 2 Out-of-school children by mobile money use

months exogenous shocks (Strobl 2017) ${ }^{18}$ or it has relocated. The rationale behind this last control stems from the fact that, as shown for instance in Amuedo-Dorantes and Pozo (2010), migration can negatively affect school attendance of children in migrant households. Apart from household's characteristics, some estimated models also include personal characteristics of the household head such as gender, rural status, literacy, and numeracy that would insure that basic financial capabilities are accounted for.

We start by estimating separate models for our main dependent variables (mobile money use). The models are estimated either by Probit (marginal effects) or by OLS in order to take into account the binary or continuous nature of the dependent variable of interest. Standard errors are robust to heteroskedasticity and data are weighted to conform to the national population. As a robustness check, we estimate the same models without weights and consider only the three countries for which mobile money penetration is greater than $20 \%$ (i.e., Kenya, Tanzania, and Uganda).

\footnotetext{
${ }^{18}$ Such as a flood, fire, or other natural disasters that have destroyed house, property or business, bad weather or pests that have destroyed all or part of crops or livestock due to a disease, an increase of costs of agricultural inputs, or other additional expenses related to household's farm or business, and a decrease in price of crop, livestock, or other goods that the household was used to sell to the market.
} 
Furthermore, as discussed above, there are several reasons to expect that the association between mobile money and out-of-school children is heterogeneous across gender. To formally test for heterogeneous effects of mobile money, Eq. (1) is estimated separately for households having girls not going to school or boys not going to school.

An important methodological issue in our analysis is the potential endogeneity of mobile money use. Endogeneity may arise from unobserved heterogeneity at the individual and household level, as mobile money use and the decision to send children to school might be jointly determined by unobserved personality traits and attitudes, such as forward looking behavior. In order to address this issue, we make use of Instrumental Variables estimation (IV). Taking into account the binary nature of our main endogenous regressor, we estimate a bivariate marginal effect Probit model consisting of two specifications, a reduced form equation for the potentially endogenous dummy of mobile money use and a structural form equation determining the outcome of interest (Heckman 1978).

More specifically, the reduced form equation includes two instruments: a proxy for access to an over-the-counter (OTC). ${ }^{19}$ and a dummy for mobile money knowledge $^{20}$ In several low-income countries, mobile money transactions are often OTC transactions. Unlike with a personal electronic mobile wallet, OTC transactions are not directly executed by the customers. Instead, they imply the mediation of an agent who receives customers' cash and executes the electronic task on their behalf. The assumption underlying the choice of this instrument is straightforward: a household living next to an OTC has a greater chance to use mobile money with respect to one living far away. Furthermore, living next to an OTC should be independently related to the decision to send children in school age to school. The rationale behind the second instrument goes in the same direction as the previous one: having a knowledge of mobile money is assumed to be a pre-condition for mobile money adoption but it is assumed to be independently related to the decision to send children in school age to school.

Although it could be plausible to assume that a household could decide to move with the explicit aim to live next to an OTC, therefore enjoying an easier access to financial services, the estimated specifications include among the controls a dummy for household's relocation during the last 12 months. Accordingly, the estimated specification includes a dummy for living below the poverty line to account for possible wealth effects affecting simultaneously mobile money knowledge and adoption, and the decision to send children to school. What we cannot really exclude as a possibility is that households sending children to school are more likely to see advertising money mobile in OTC near the school where their children go, so that they

\footnotetext{
19 "If you had to go to the closest over the counter in a branch of a bank, how much time it would take you? I want to know, if you use your typical mode of transport or walk or ride a bicycle, whatever you usually do-how long would it take you to get there? It does not matter if you use it or not-I just want to know how far it is from you." With possible answers being $0.5 \mathrm{~km}$ or less (1), More than $0.5 \mathrm{~km}$ to 1 $\mathrm{km}$ (2), More than $1 \mathrm{~km}$ to $5 \mathrm{~km}$ (3), More than $5 \mathrm{~km}$ to $10 \mathrm{~km}$ (4), More than $10 \mathrm{~km}$ to $15 \mathrm{~km}(5)$, More than $15 \mathrm{~km}(6)$.

20 "Have you ever heard of something called Mobile Money?".
} 
change their knowledge of this tool and their decision to adopt it simultaneously. In the same vein, given data limitations, we are not able to show that the placement of mobile money agents is random, as it was the case in Jack and Suri (2014). If agents choose their location near schools, because this is positive for their business, the IV strategy is no longer valid.

Given these limitations and the impossibility of finding more suitable instruments, the results of the Instrumental Variables estimation must be interpreted with caution and in the light of the entire analysis including propensity score matching and robustness checks. We will therefore not give a causal interpretation to our results and will leave it to future work.

\section{Results}

This section presents the results of the empirical analysis. We start by estimating the association between mobile money and the probability that a household has children (boys and girls, respectively) in school age that do not attend school. We focus on the association between mobile money, while controlling for a wide set of control variables as described in Eq. (1). We then present some robustness checks and Instrumental Variables estimations.

\section{Mobile Money and Schooling}

Table 2 presents the results obtained on the whole sample. In order to check the robustness of the results, we consider four alternative specifications. Columns 1-2 report the results of estimating Eq. (1) while using as dependent variable a dummy indicating whether the household has children (boys in Column 1 and girls in Column 2, respectively) in school age that do not attend school. Columns 3-4 report the results of estimating Eq. (1) while using as dependent variable the share of children in the household in school age that do not attend school (boys in Column 3 and girls in Column 4, respectively). The models depicted in Columns 1-2 are estimated by Probit (marginal effect) while those depicted in Columns 3-4 are estimated by OLS. All models include country and year-fixed effects.

We first consider the results for the covariates, in order to provide a preliminary assessment of the specification used in the empirical analysis. The estimates for the different specifications are qualitatively similar across models. Several variables turn out to be significant. Households' wealth (proxied by either transfers received or the probability of being below the poverty line) has a significant effect in terms of household's decision to send children to school suggesting that, in line with Basu and Van (1998), household's financial situation matters. Having experienced natural shocks affects negatively school participation. Overall, these results are consistent with those generally found in the literature.

The results for mobile money usage are consistent with our main hypothesis: households using mobile money services are less likely to have children in school age that do not attend school. This effect is always slightly greater for boys with 
Table 2 Associations between mobile money and schooling

(1)

(3)

(4)

The household has children not going to school

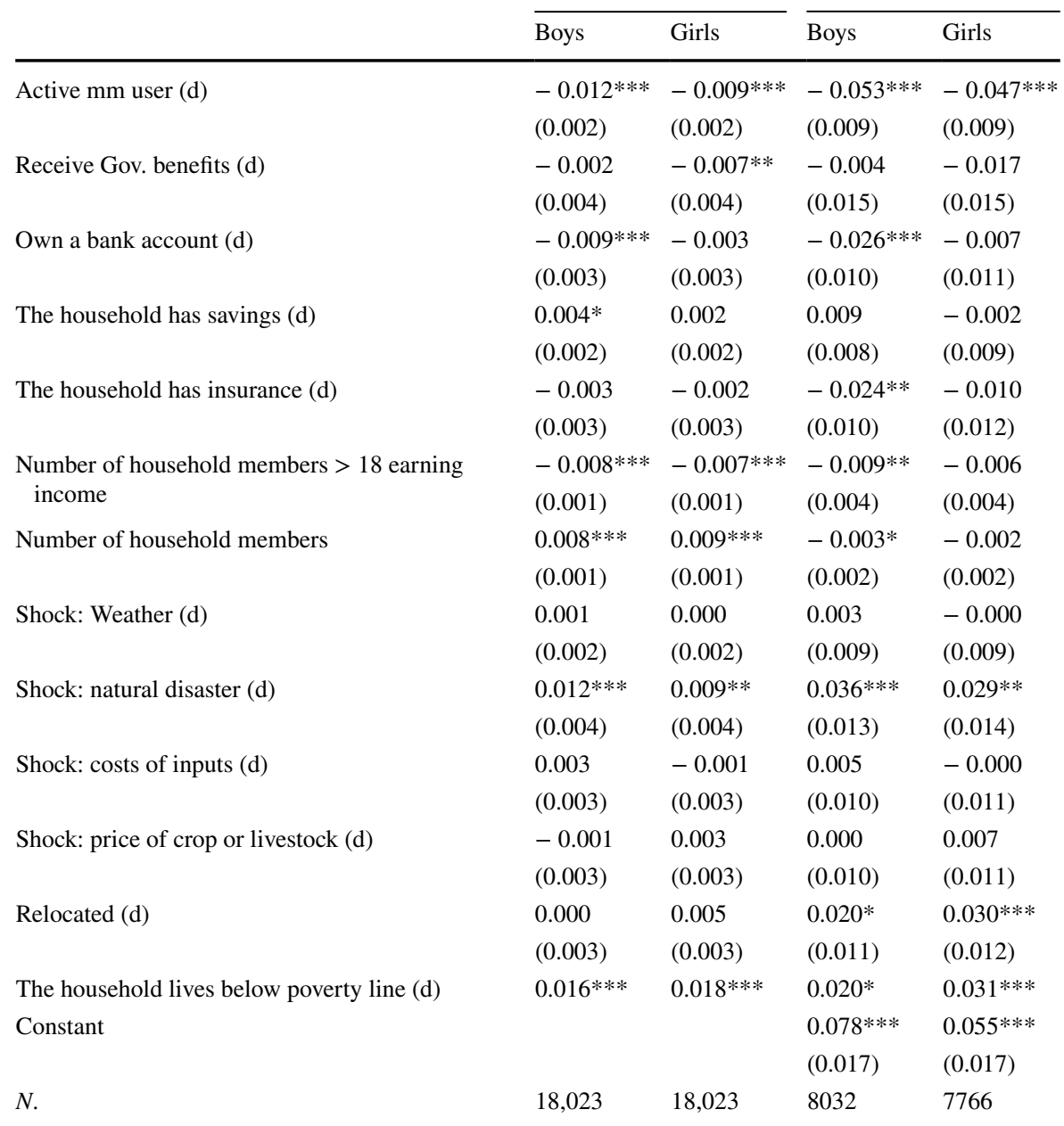

Covariates as described in Table 1. All reported models include country and year dummies. Columns 1-2 Probit marginal effects. Columns 3-4 OLS. Standard errors robust to heteroskedasticity reported in brackets

$* p<0.10, * * p<0.05, * * * p<0.01$

respect to girls suggesting that in the decision to send girls to school increasing financial inclusion and improving financial access could have a different impact across children's gender. Specifically, households with at least one mobile money user are 1.2 and 0.9 percentage points less likely to have boys and girls, respectively, in school age that do not attend school. 
Table 3 Associations between mobile money and schooling: interaction with shocks

(1) (2)

The household has children not going to school

\begin{tabular}{llllll}
\cline { 6 - 6 } \cline { 5 - 6 } \cline { 5 - 6 } & Boys & Girls & & Boys & Girls \\
\hline Active*Shock (d) & $-0.012^{* * * *}$ & $-0.009^{* * *}$ & & $-0.062^{* * *}$ & $-0.041^{* *}$ \\
& $(0.003)$ & $(0.004)$ & & $(0.015)$ & $(0.016)$ \\
Active mm user (d) & -0.005 & -0.003 & & -0.017 & $-0.024^{*}$ \\
& $(0.003)$ & $(0.003)$ & & $(0.013)$ & $(0.013)$ \\
Exogenous shock (d) & $0.010^{* *}$ & $0.008^{*}$ & & $0.041^{* *}$ & $0.032^{*}$ \\
& $(0.004)$ & $(0.004)$ & & $(0.016)$ & $(0.017)$ \\
Constant & & & $0.058^{* * *}$ & $0.041^{* *}$ \\
& & & $(0.018)$ & $(0.017)$ \\
$N$. & 18,023 & 18,023 & 8032 & 7766 \\
\hline
\end{tabular}

Covariates as described in Table 1. All reported models include country and year dummies. Columns 1-2 Probit marginal effects. Columns 3-4 OLS. Shock $=1$ when the household has faced any of the shocks depicted in Table 1. (d) indicates discrete change of dummy variable from 0 to 1 . Standard errors robust to heteroskedasticity reported in brackets

$* p<0.10, * * p<0.05, * * * p<0.01$

Table 4 Associations between mobile money and schooling: robustness

\begin{tabular}{|c|c|c|c|c|c|c|}
\hline & (1) & (2) & (3) & (4) & (5) & (6) \\
\hline & \multicolumn{2}{|c|}{$\begin{array}{l}\text { Sample restricted to } 3 \\
\text { Countries }\end{array}$} & \multicolumn{2}{|c|}{ Non-weighted regression } & \multicolumn{2}{|c|}{$\begin{array}{l}\text { Propensity score match- } \\
\text { ing }\end{array}$} \\
\hline & Boys & Girls & Boys & Girls & Boys & Girls \\
\hline Active mm user (d) & $\begin{array}{l}-0.012 * * * \\
(0.003)\end{array}$ & $\begin{array}{l}-0.008^{* * *} \\
(0.003)\end{array}$ & & & & \\
\hline Active mm user (d) & & & $\begin{array}{l}-0.013 * * * \\
(0.002)\end{array}$ & $\begin{array}{l}-0.009 * * * \\
(0.002)\end{array}$ & & \\
\hline Active mm user (d) & & & & & $\begin{array}{l}-0.019 * * * \\
(0.003)\end{array}$ & $\begin{array}{l}-0.010^{* * *} \\
(0.004)\end{array}$ \\
\hline$N$ & 12,023 & 12,023 & 18,023 & 18,023 & 18,023 & 18,023 \\
\hline
\end{tabular}

Dependent variable: The household has boys/girls not going to school. Covariates as described in Table 1. All reported models include country and year dummies. Probit marginal effects or PSM. Standard errors robust to heteroskedasticity reported in brackets

${ }^{*} p<0.10,{ }^{* *} p<0.05, * * * p<0.01$

The size of the coefficient is small in absolute terms. In relative terms, however, the size of the coefficient of mobile money is sizable, being at least as large than that of owning a bank account ( -0.9 and -0.3 , respectively, in Column 1 and 2). 
Table 5 Associations between mobile money and schooling: robustness

(1)

The household has boys not going to school
(2)

The household has girls not going to school

\begin{tabular}{lll}
\hline Active mm user (d) & -0.003 & $-0.004^{* *}$ \\
& $(0.002)$ & $(0.002)$ \\
The household below poverty line (d) & $0.008^{* * *}$ & $0.011^{* * *}$ \\
& $(0.003)$ & $(0.004)$ \\
The household head: rural female (d) & 0.002 & -0.003 \\
& $(0.002)$ & $(0.002)$ \\
Literacy (d) & $-0.004^{*}$ & -0.000 \\
Numeracy (d) & $(0.002)$ & $(0.002)$ \\
& -0.000 & -0.001 \\
$N$. & $(0.003)$ & $(0.004)$ \\
Standard controls & 8491 & 8491 \\
\hline
\end{tabular}

Covariates as described in Table 1 . All reported models include country and year dummies. Probit marginal effects. Standard errors robust to heteroskedasticity reported in brackets. Sample restricted to observations for which we do have information regarding the head of the household

$* p<0.10,{ }^{* *} p<0.05, * * * p<0.01(\mathrm{~d})$ indicates discrete change of dummy variable from 0 to 1

Consistent with the previous literature (Riley 2018; Tabetando and Matsumoto 2020) and with our main interpretation, Table 3 shows that households using mobile money tend to cope better with exogenous shocks, as described in Table 1.

\section{Robustness}

To assess the robustness of our main result, we conduct some sensitivity tests of the main estimates to the use of different samples, estimation techniques, and specifications.

First, we estimate the model in Eq. (1) when restricting the sample to Kenya, Tanzania, and Uganda, the 3 countries where mobile money usage rate is higher than 20\% (Columns 1-2 in Table 4), and without weighting the data (Columns 3-4 in Table 4). As an additional way of studying the above presented relationship, we also present results obtained by applying a propensity score matching (PSM) estimator to the data (Columns 5-6 in Table 4). Though PSM could be seen as a good method to evaluate the causal effect of a treatment absent randomization, its main limitation is that it only accounts for observable covariates. As a result, any bias due to latent variables may remain after matching. The main finding of a positive association between mobile money and schooling remains statistically significant and comparable in size across models and estimation techniques.

Second, Table 5 shows that the main result, although smaller in size, still holds for girls (not for boys) when we control for characteristics of the household head 
Table 6 Associations between mobile money and schooling, instrumental variables

(1) (2)

First stage: active mm IV: Boys user

$-0.024 * * *$

(0.002)

Access to OTC

\begin{tabular}{llll}
\hline Knows mobile money service & $\begin{array}{l}0.141^{* * *} \\
(0.009)\end{array}$ & \\
Access to OTC & $-0.024^{* * *}$ & & \\
& $(0.002)$ & & \\
Active mm user (d) & & $-0.022^{* * *}$ & $-0.022^{* * *}$ \\
& & $(0.003)$ & $(0.003)$ \\
Athrho & $0.092^{*}$ & $0.150^{* *}$ \\
Hansen J statistic & $\chi^{2}=0.557$ & $\chi^{2}=0.211$ \\
& & $p=0.455$ & $p=0.646$ \\
$N$. & 15,269 & 15,269 & 15,269 \\
\hline
\end{tabular}

Active mm user (d)

Athrho

Hansen J statistic

$N$.

15,269

(3)

IV: Girls

Covariates as described in Table 1. Seemingly unrelated bivariate Probit. First stage reported only for column 2. First stage for column 3 available upon request

$* p<0.10, * * p<0.05, * * * p<0.01$

such as gender, rural status, literacy, and numeracy that would insure that basic financial capabilities are accounted for. Note that the size of the coefficient for literacy is only half that for poverty suggesting that, as argued in Lutz (2017), education is an essential prerequisite for enabling people to eradicate poverty and an engine for self-development.

\section{Accounting for Endogeneity}

The results of the empirical analysis have so far provided robust evidence of a positive relationship between mobile money and school participation of children in school age. However, as already stated above, we cannot rule out the possibility that the error term in Eq. (1) is related to the regressors, due to unobserved heterogeneity or simultaneity. The cross-sectional nature of the dataset does not provide a within-subject variation that could be exploited in order to improve the identification strategy. As a result, we turn to the use of an instrumental variable (IV) estimator. This estimator is consistent only under the assumption of instrument validity, i.e., when the instruments are correlated with the endogenous regressor (i.e., mobile money) and uncorrelated with the error term (the dependent variable, i.e., children in school).

Table 6 reports IV estimation results. Column 1 of Table 6 reports the first-stage equation. Both instruments have the expected sign and are significantly related to the endogenous variables.

The IV estimates of the association between mobile money and the probability of having children in the household that do not attend school are negative and significant. Indeed, the size of the estimated effect is slightly larger when using IV, consistently with a measurement error bias driving the Probit estimates towards 
zero or with the fact that the estimated coefficients recover, indeed, local average treatment effects (LATE) rather than average treatment effects (ATE). This means that the effect of mobile money is only revealed for the subpopulation of compliers: those which would use mobile money if mobile money were present but which would not use it if mobile money were absent.

A test of over-identifying restrictions is reported at the bottom of Table 6. The specification in columns 2 and 3 shows a non-significant chi-square statistic, suggesting that the joint validity of the instruments is not rejected.

\section{Conclusions}

Mobile phones are rapidly spreading in low-income countries and, with them, their potential especially for poor people in rural areas. One interesting and potentially revolutionary contribution of mobile phones technology to development is through the use of mobile money services, a simple and relatively cheap innovation with the potential to reach the unbanked and increase financial inclusion.

In this paper, we have studied the association between mobile money and out-ofschool children by exploiting the richness of the InterMedia's Financial Inclusion set of nationally representative sample surveys for Kenya, Nigeria, Tanzania, and Uganda. Our results suggest that mobile money technology increases the chances of children attending school. Specifically, households with at least one mobile money user are 1.2 and 0.9 percentage points less likely to have boys and girls, respectively, in school age that do not attend school. While the size of the coefficient is small in absolute terms, it is sizable in relative terms, being at least as large than that of owning a bank account.

Our results are largely consistent across the different model specifications and samples and are robust to methods aimed at addressing the potential endogeneity of mobile money use.

Our study complements the growing literature on the associations between mobile money and households' welfare in low-income countries and has a strong policy implication: mobile money services can play a pivotal role as a flywheel for development and, in particular, as a driving force for inclusive growth and shared prosperity by helping to reach "inclusive and equitable quality education for all" by 2030. The availability of this cheap innovation, in fact, can relax households' liquidity constraints and, therefore, can reduce detrimental coping strategies in the face of income shocks such as pulling children from school to work. Since attitudes and identities are formed at a younger age, and are largely maintained throughout the lifespan, an improvement, however small, in terms of schooling and education can have important long-lasting effects. The literature shows that an increased access to education can lead, among other things, to better institutions (Glaeser et al. 2007; Lutz et al. 2010), to more weight-tested fertility decisions (Duflo et al. 2015; Shapiro and Gebreselassie 2013; Lutz 2014), to a more future-oriented society caring also for the environment (Inglehart 1995) and to greater gender egalitarianism (Pampel 2011). In a nutshell, applying our estimate to UNESCO's data (UNESCO 2016), more than 1 million children could start attending school in low-income countries 
if mobile money was available to all. With the maturation of the technology and with the increasing potential of mobile money platforms, the impact of this tool on education could even grow. In Uganda, for instance, parents can now make use of a flexible education loan through their mobile money wallets. GSMA (2020) estimates that in households using this product, only $15 \%$ of students missed a day of school for motivations related to non-payment compared to $24 \%$ of students in households that did not use the product. The insights presented here, therefore, once more show that ICT technologies in general, and mobile money technology in particular, can be powerful tools to attain sustainable development, in an ultimate effort to enhance well-being and reduce poverty (Rotondi et al. 2020).

Follow-up research should analyze how the access to mobile money could improve not only the probability of being enrolled at school but also to complete education by accounting also for birth order and sibling composition that play an important role in children's allocation of time (Dammert 2010), two aspects neglected in this paper due to data limitations. In doing so, further research could make use of panel data that are better suited for rigorous analytical purposes. A rather neglected aspect deserving further attention is the analysis of the effect of mobile money on paid child work and, more general, on the underground and informal economy.

Funding This project has received funding from the European Research Council (ERC) under the European Union's Horizon 2020 research and innovation programme (Grant Agreement n. 694262), project DisCont-Discontinuities in Household and Family Formation. We are grateful to Nicoletta Balbo, Pierluigi Conzo, Chiara Falco, Rachel Heath, Ridhi Kashyap, Alessandro Di Nallo, Andrew Foster, Luca Pesando, Luca Stanca, and Luca Stella for comments and suggestions.

Data Availability Data can be requested at the following link: http://finclusion.org. The code will be made available upon acceptance.

\section{Compliance with Ethical Standards}

Conflict of interest The authors have no conflict of interest to disclose

Open Access This article is licensed under a Creative Commons Attribution 4.0 International License, which permits use, sharing, adaptation, distribution and reproduction in any medium or format, as long as you give appropriate credit to the original author(s) and the source, provide a link to the Creative Commons licence, and indicate if changes were made. The images or other third party material in this article are included in the article's Creative Commons licence, unless indicated otherwise in a credit line to the material. If material is not included in the article's Creative Commons licence and your intended use is not permitted by statutory regulation or exceeds the permitted use, you will need to obtain permission directly from the copyright holder. To view a copy of this licence, visit http://creativecommons.org/licen ses/by/4.0/.

\section{References}

Adams, R. H., \& Cuecuecha, A. (2013). The impact of remittances on investment and poverty in Ghana. World Development, 50, 24-40. 
Amuedo-Dorantes, C., \& Pozo, S. (2010). Accounting for remittance and migration effects on children's schooling. World Development, 38(12), 1747-1759.

Azizi, S. (2018). The impacts of workers' remittances on human capital and labor supply in developing countries. Economic Modelling, 75, 377-396.

Azizi, S. (2019). The impacts of workers' remittances on poverty and inequality in developing countries. Empirical Economics, 1-23.

Azizi, S. (2020). Impacts of remittances on financial development. Journal of Economic Studies, 47(3), $467-477$.

Baland, J.-M., \& Robinson, J. A. (2000). Is child labor inefficient? Journal of Political Economy, 108(4), 663-679.

Bargain, O., \& Boutin, D. (2015a). Remittance effects on child labour: Evidence from Burkina Faso. The Journal of Development Studies, 51(7), 922-938.

Bargain, O., \& Boutin, D. (2015b). Remittance effects on child labour: Evidence from Burkina Faso. The Journal of Development Studies, 51(7), 922-938.

Barro, R. J., \& Lee, J. W. (2013). A new data set of educational attainment in the world, 1950-2010. Journal of Development Economics, 104, 184-198.

Basu, K., Das, S., \& Dutta, B. (2010). Child labor and household wealth: Theory and empirical evidence of an inverted-u. Journal of Development Economics, 91(1), 8-14.

Basu, K., \& Van, P. H. (1998). The economics of child labor. American Economic Review, 88, 412-427.

Beegle, K., Dehejia, R. H., \& Gatti, R. (2006). Child labor and agricultural shocks. Journal of Development Economics, 81(1), 80-96.

Bhalotra, S., \& Heady, C. (2003). Child farm labor: The wealth paradox. The World Bank Economic Review, 17(2), 197-227.

Binci, M., \& Giannelli, G. C. (2016). Internal versus international migration: Impacts of remittances on child labor and schooling in Vietnam. International Migration Review.

Björkman-Nyqvist, M. (2013). Income shocks and gender gaps in education: Evidence from Uganda. Journal of Development Economics, 105, 237-253.

Clark, R. (2011). Child labor in the world polity: Decline and persistence, 1980-2000. Social Forces, 89(3), 1033-1055.

Coon, M. (2016). Remittances and child labor in Bolivia. IZA Journal of Migration, 5(1), 1.

Dammert, A. C. (2010). Siblings, child labor, and schooling in Nicaragua and Guatemala. Journal of Population Economics, 23(1), 199-224.

De Janvry, A., Finan, F., Sadoulet, E., \& Vakis, R. (2006). Can conditional cash transfer programs serve as safety nets in keeping children at school and from working when exposed to shocks? Journal of Development Economics, 79(2), 349-373.

Dehejia, R. H., \& Gatti, R. (2005). Child labor: The role of financial development and income variability across countries. Economic Development and Cultural Change, 53(4), 913-931.

Delap, E. (2001). Economic and cultural forces in the child labour debate: Evidence from urban Bangladesh. Journal of Development Studies, 37(4), 1-22.

Dillon, A. (2013). Child labour and schooling responses to production and health shocks in northern Mali. Journal of African Economies, 22(2), 276-299.

Duflo, E., Dupas, P., \& Kremer, M. (2015). Education, HIV, and early fertility: Experimental evidence from Kenya. The American Economic Review, 105(9), 2757-2797.

Dumas, C. (2007). Why do parents make their children work? A test of the poverty hypothesis in rural areas of Burkina Faso. Oxford Economic Papers, 59(2), 301-329.

Edmonds, E. V., \& Pavcnik, N. (2005). Child labor in the global economy. The Journal of Economic Perspectives, 19(1), 199-220.

Edmonds, E. V., \& Shrestha, M. (2014). You get what you pay for: Schooling incentives and child labor. Journal of Development Economics, 111, 196-211.

Filmer, D. (2005). Gender and wealth disparities in schooling: Evidence from 44 countries. International Journal of Educational Research, 43(6), 351-369.

Fors, H. C. (2012). Child labour: A review of recent theory and evidence with policy implications. Journal of Economic Surveys, 26(4), 570-593.

Glaeser, E. L., Ponzetto, G. A., \& Shleifer, A. (2007). Why does democracy need education? Journal of Economic Growth, 12(2), 77-99.

GSMA. (2017). State of the Industry Report on Mobile Money. GSMA. 
GSMA. (2020). Harnessing the power of mobile money to achieve the sustainable development goals.

Guarcello, L., Mealli, F., \& Rosati, F. C. (2010). Household vulnerability and child labor: The effect of shocks, credit rationing, and insurance. Journal of Population Economics, 23(1), 169-198.

Hazarika, G., \& Bedi, A. (2003). Schooling costs and child work in rural Pakistan. The Journal of Development Studies, 39(5), 29-64.

Heckman, J. J. (1978). Dummy endogenous variables in a simultaneous equation system. Econometrica, 46(4), 931-959.

Inglehart, R. (1995). Public support for environmental protection: Objective problems and subjective values in 43 societies. PS: Political Science \& Politics, 28(1), 57-72.

Jack, W., \& Suri, T. (2014). Risk sharing and transactions costs: Evidence from Kenya's mobile money revolution. American Economic Review, 104(1), 183-223.

Kambhampati, U. S., \& Rajan, R. (2006). Economic growth: A panacea for child labor? World Development, 34(3), 426-445.

Kikulwe, E. M., Fischer, E., \& Qaim, M. (2014). Mobile money, smallholder farmers, and household welfare in Kenya. PLoS ONE, 9(10), e109804.

Kruger, D. I. (2007). Coffee production effects on child labor and schooling in rural Brazil. Journal of Development Economics, 82(2), 448-463.

Ky, S., Rugemintwari, C., \& Sauviat, A. (2017). Does mobile money affect saving behaviour? Evidence from a developing country. Journal of African Economies, 27(3), 285-320.

Lutz, W. (2014). A population policy rationale for the twenty-first century. Population and Development Review, 40(3), 527-544.

Lutz, W. (2017). Global sustainable development priorities 500 y after luther: Sola schola et sanitate. Proceedings of the National Academy of Sciences, 114(27), 6904-6913.

Lutz, W., Cuaresma, J. C., \& Abbasi-Shavazi, M. J. (2010). Demography, education, and democracy: Global trends and the case of Iran. Population and Development Review, 36(2), 253-281.

Mbiti, I., \& Weil, D. N. (2011). Mobile banking: The impact of m-pesa in Kenya. National Bureau of Economic Research.

Mendola, M. (2016). How does migration affect child labor in sending countries? IZA World of Labor.

Munyegera, G. K., \& Matsumoto, T. (2016). Mobile money, remittances, and household welfare: Panel evidence from rural Uganda. World Development, 79, 127-137.

Murendo, C., \& Wollni, M. (2016). Mobile money and household food security in Uganda. GlobalFood Discussion Papers.

Pampel, F. (2011). Cohort change, diffusion, and support for gender egalitarianism in cross-national perspective. Demographic Research, 25, 667.

Pouliot, W. (2006). Introducing uncertainty into Baland and Robinson's model of child labour. Journal of Development Economics, 79(1), 264-272.

Ranjan, P. (2001). Credit constraints and the phenomenon of child labor. Journal of Development Economics, 64(1), 81-102.

Rankin, B. H., \& Aytaç, I. A. (2006). Gender inequality in schooling: The case of Turkey. Sociology of Education, 79(1), 25-43.

Riley, E. (2018). Mobile money and risk sharing against village shocks. Journal of Development Economics, $135,43-58$

Rotondi, V., Kashyap, R., Pesando, L., Spinelli, S., \& Billari, F. C. (2020). Leveraging mobile phones to attain sustainable development. Proceedings of the National Academy of Sciences, 117(24), 13413-13420.

Shapiro, D., \& Gebreselassie, T. (2013). Fertility transition in sub-Saharan Africa: Falling and stalling. African Population Studies, 23(1), 3-23.

Soares, R. R., Kruger, D., \& Berthelon, M. (2012). Household choices of child labor and schooling a simple model with application to Brazil. Journal of Human Resources, 47(1), 1-31.

Strobl, R. (2017). Does health insurance reduce child labour and education gaps? Evidence from Rwanda. The Journal of Development Studies, 53(9), 1376-1395.

Suri, T., \& Jack, W. (2016). The long-run poverty and gender impacts of mobile money. Science, 354(6317), $1288-1292$.

Tabetando, R., \& Matsumoto, T. (2020). Mobile money, risk sharing, and educational investment: Panel evidence from rural Uganda. Review of Development Economics, 24(1), 84-105.

The World Bank. (2015). The little data book on financial inclusion. Washington, DC: World Bank Publications.

UNESCO. (2015). Pricing the right to education: The cost of reaching new targets by 2030. Paris: UNESCO. 
UNESCO. (2016). Leaving no one behind: How far on the way to universal primary and secondary education?. Paris: UNESCO Institute for Statistics (UIS).

Vasconcelos (2017). Sending money hom: Contributing to the SDGs, one family at a time. Rome, Italy: International Fund for Agricultural Development.

Publisher's Note Springer Nature remains neutral with regard to jurisdictional claims in published maps and institutional affiliations. 